\title{
EFFECT OF SUPPLEMENTING MORINGA OLEIFERA LEAF EXTRACT AND CLOVE BUD OIL TO THE DIET ON MICROFLORA POPULATION AND INTESTINAL MORPHOLOGY OF BROILER BIRDS
}

\author{
J. CHAKMA ${ }^{1}$, A. K. SAMANTA ${ }^{1 *}$, T. K. DUTTA ${ }^{2}$ AND R. S. ARYA ${ }^{3}$
}

\author{
${ }^{1}$ Department of Animal Nutrition, College of Veterinary Sciences \& Animal Husbandry, Central \\ Agricultural University, Selesih, Aizawl-796 014, Mizoram, India \\ ${ }^{2}$ Department of Veterinary Microbiology, College of Veterinary Sciences \& Animal Husbandry, \\ Central Agricultural University, Selesih, Aizawl- 796 014, Mizoram, India \\ ${ }^{3}$ Department of Veterinary Pathology, College of Veterinary Sciences \& Animal Husbandry, Central \\ Agricultural University, Selesih, Aizawl- 796 014, Mizoram, India
}

\begin{abstract}
The present experiment was carried out to assess the effect of Moringa oleifera leaf extract and clove (Syzygium aromaticum) bud oil on the intestinal gut morphology and microbial status of broiler birds. Two hundred broiler chicks (day old) were randomly distributed into five treatment groups. Dietary supplemented groups were comprised of Group-1 (control); Group- 2 (basal diet with Bacitracin methylene disalicylate @ $0.5 \mathrm{~g} / \mathrm{kg}$ of feed); Group-3 (basal diet with Moringa oleifera extract @ $0.55 \mathrm{~g} / \mathrm{kg}$ of feed); Group- 4 (basal diet supplemented with clove bud oil @ $0.6 \mathrm{~g} / \mathrm{kg}$ of feed) and Group- 5 (diet supplemented with Moring a oleifera extract and clove bud oil combination at same dose rate respectively). Result revealed that Salmonella spp. and $E$. coli counts in caecum were found similar $(P>0.05)$ across different treatment groups but Lactobacillus spp. count tended $(P=0.10)$ to be higher for group-3, group-4 and group-5 as compared to control and antibiotic fed group. Intestinal histomorphological studies showed significant difference $(P<0.05)$ in villi height to crypt depth ratio (VH/CD) of duodenum of experimental birds in group-3 in comparison to other groups. VH/CD ratio of jejunum and ileum were tended to be higher $(P=0.07$ and $P=0.06$ respectively $)$ in antibiotic, Moringa plant extract and clove oil supplemented group than control. The finding might have resulted from a controlled damage to the enterocytes, thus reducing the nutrient requirement for their turnover in $M$. oliefera and clove bud oil supplemented groups. It can be concluded that Moringa oliefera leaf extract and clove bud oil have the potential to be used as an alternative to antibiotic growth promoter to improve the health status of broiler birds.
\end{abstract}

Key words: Broiler, Intestinal morphology, Microflora, Moringa oleifera, Syzygium aromaticum oil

\section{INTRODUCTION}

Poultry industry has been growing at faster rate in India. Antibiotic growth promoters (AGP) have been used as feed additive in poultry industry to enhance gut health and to control sub-clinical diseases (David et al., 2012). Antibiotics have generated resistant strains by transferring resistance to other species and made serious problem in public health and livestock. Since $1^{\text {st }}$ January 2006, use of in-feed antibiotics as growth promoters was banned by European countries (Catala-Gregori et al., 2008). Therefore, several researchers had searched for alternatives to AGP such as, organic acids, phytobiotics, bacteriophages, probiotics and prebiotic (Yan et al., 2012). Phytobiotics (essential oil, herbs, spices, and various plant extracts) are among those potential alternative to antibiotic growth promoters, which have received expansion 
as potential alternative to AGP. M. oleifera leaves are traditionally used widely for its antimicrobial properties (Suarez et al., 2005) and its pharmacological effects (Mehta et al., 2003). Clove found to inhibit some gut microbes and acts as an antiseptic and digestion stimulant, and has powerful antifungal and antimicrobial activity, anti-inflammatory, anti-carcinogenic and antioxidant effects (Ehrlich et al., 1995; Mitsch et al., 2004; Najafi and Torki, 2010). Eugenol, an active principle present in clove oil has antimicrobial (Ehrlich et al., 1995), and antiinflammatory (Feng and Lipton, 1987). Briozzo et al. (1989) revealed that clove oil with its active compound eugenol, destroy Clostridium perfringes and other bacteria. Hence, the present study was carried out to investigate the effect of $M$. oliefera and clove bud oil supplementation on microbial status and intestinal morphology of broiler birds.

\section{MATERIALS AND METHODS}

Two hundred $(n=200)$ day old chicks (Vencobb) were distributed randomly into five treatment groups with five replicates $(n=5)$ per group. Each replicate comprised of 8 chicks and five dietary groups consisted of: Group-1 (control) birds were fed basal diet; Group-2 (AB) were fed basal diet with Bacitracin methylene disalicylate @ $0.5 \mathrm{~g} / \mathrm{kg}$ of feed; Group-3 (MPE) were fed basal diet with Moringa oleifera crude extract @ $0.55 \mathrm{~g} / \mathrm{kg}$ of feed; Group-4 (CBO) had received the basal diet supplemented with clove bud oil $@ 0.6 \mathrm{~g} / \mathrm{kg}$ of feed and birds in Group-5 (MPCBO) had received the basal diet supplemented with Moringa oleifera crude extract and clove bud oil combination at same dose rate respectively. The experimental house, feeder and watering trough were properly cleaned and poultry house was disinfected by white washing the floor and walls. All the birds were vaccinated against to Newcastle disease and Infectious Bursal disease. The chickens were housed in floor pen on fresh rice husk and saw dust. Three types of standard diet of broiler were prepared i.e. broiler pre-starter (1-7 days of age), starter (8-21 days of age) and finisher (22-42 days of age) as per BIS (2007) specification. Moringa oleifera leaves were processed and the acetonic extract for the plants were prepared following the standard procedure. Level of inclusion of plant extracts and clove oil were considered based on minimum inhibition concentration (MIC). Antimicrobial activity of the M. oleifera extracts was done by disc diffusion method (CLSI, 2008). Clove bud oil was purchased from Allin exporters, New Delhi, India.

Microbial status in caecum of broiler birds: The pre-caecal contents of the intestine were collected aseptically from the birds after slaughter on $42^{\text {nd }}$ day of the trial. The pre-caecal contents were stored at $4^{\circ} \mathrm{C}$ and bacteriological enumeration was performed on the same day. Serial dilution of $1 \mathrm{~g}$ of the pre-caecal content was done (10-fold) with sterile phosphate buffer saline (PBS). Each dilution $(10 \mu \mathrm{L})$ was poured on Nutrient agar (HiMedia, India), MRS agar (HiMedia, India), SS agar (HiMedia, Mumbai, India) and EMB agar (HiMedia, Mumbai, India), for finding the count of total bacteria, Lactobacillus spp., Salmonella spp. and E.coli respectively. The plates were incubated aerobically at $37^{\circ} \mathrm{C}$ for $24 \mathrm{~h}$. The colonies of bacteria were enumerated in a colony counter (hand held digital colony counter, LA663, Himedia Lab. Pvt. Ltd., Mumbai, India) and the numbers were expressed as $\log _{10}$ colony forming units (CFU) per gram of sample.

\section{Histo-morphological study of small intestine:} Five chickens from each dietary treatment were slaughtered on $42^{\text {nd }}$ day by cervical disarticulation for the measurement of height of the intestinal villus and crypt depth. About 2 to $3 \mathrm{~cm}$ sections of duodenum, jejunum and ileum were removed and washed with PBS. Cross section $(1 \mathrm{~cm})$ was fixed in $10 \%$ buffered 
formaldehyde ( $\mathrm{pH}$ 7.2) for about 1-2 weeks, followed by paraffin wax embedding. With Delafield's Hematoxyline and Eosin, the tissue slides were stained, and mounted on distrene plasticiser xylene based on protocol described by Incharoen et al. (2009). All measurements were taken with Advanced Olympus trinocular research microscope.

Statistical analysis: The data were analyzed by one-way ANOVA using SPSS software in a completely randomized design as per the procedure described by Snedecor and Cochran (1994). Probability values $\mathrm{P} \leq 0.05$ were declared as significant and the values of $0.05>$ $\mathrm{P} \leq 0.10$ were declared as trend.

\begin{abstract}
RESULTS
Microbial status in caecum of broiler birds: There were no significance difference $(\mathrm{P}>0.05)$ in the counts of total bacteria, Salmonella spp., E.coli spp. and Lactobacillus spp. of experimental birds among different treatment groups (Table 1). However, the counts of Lactobacillus spp. was tended to be higher $(\mathrm{P}=0.10)$ in Moringa plant extract and clove oil supplemented groups than antibiotic and control group.
\end{abstract}

Histo-morphological of small intestine: Morphometric measurements obtained for small intestines of experimental broiler chickens (duodenum, jejunum and ileum) are presented in Table 2. The villi height, crypt depth, VH/CD ratio

Table 1. Caecal bacterial count $\left(\log _{10} \mathrm{CFU} / \mathrm{g}\right)$ of experimental broiler birds fed diet supplemented with Moringa oleifera extract and clove bud oil

\begin{tabular}{llllllll}
\hline Bacteria & Control & AB & MPE & CBO & MPCBO & SEM & P value \\
\hline Total bacteria & 6.05 & 5.79 & 6.25 & 5.97 & 6.08 & 0.113 & 0.81 \\
Lactobacillus spp. & 5.38 & 5.86 & 6.01 & 6.01 & 6.03 & 0.09 & 0.10 \\
Salmonella spp. & 5.61 & 4.98 & 4.96 & 5.48 & 4.96 & 0.11 & 0.17 \\
E. coli & 5.35 & 5.10 & 4.81 & 4.46 & 4.84 & 0.12 & 0.22 \\
\hline
\end{tabular}

AB- Antibiotic; MPE- Moringa plant extract; CBO- Clove bud oil; MPCBO- Moringa plant extract and clove bud oil

Table 2. Effect of supplementation of Moringa oleifera extract and clove bud oil on intestinal morphology in broiler chickens

\begin{tabular}{|c|c|c|c|c|c|c|c|}
\hline Attributes & Control & $\mathbf{A B}$ & MPE & CBO & MPCBO & SEM & $P$ value \\
\hline \multicolumn{8}{|l|}{ Duodenum } \\
\hline Villus height $(\mu \mathrm{m})$ & 2169.5 & 2245.1 & 2238.8 & 2245.4 & 2237.6 & 16.68 & 0.29 \\
\hline Crypt depth $(\mu \mathrm{m})$ & 207.76 & 212.88 & 176.17 & 196.36 & 201.49 & 4.87 & 0.12 \\
\hline Villus height/ crypt depth & $10.47^{\mathrm{a}}$ & $10.55^{\mathrm{a}}$ & $12.77^{\mathrm{b}}$ & $11.46^{\mathrm{a}}$ & $11.18^{\mathrm{a}}$ & 0.27 & $0.028 *$ \\
\hline \multicolumn{8}{|l|}{ Jejunum } \\
\hline Villus height $(\mu \mathrm{m})$ & 1361.5 & 1408.8 & 1433.7 & 1396.6 & 1411.2 & 10.11 & 0.24 \\
\hline Crypt depth $(\mu \mathrm{m})$ & 171.74 & 158.87 & 161.37 & 172.54 & 158.67 & 2.44 & 0.15 \\
\hline Villus height/ crypt depth & 7.93 & 8.89 & 8.89 & 8.11 & 8.90 & 0.15 & 0.07 \\
\hline \multicolumn{8}{|l|}{ Ileum } \\
\hline Villus height $(\mu \mathrm{m})$ & 1015.5 & 1074.7 & 1079.8 & 1067.1 & 1062.7 & 11.21 & 0.41 \\
\hline Crypt depth $(\mu \mathrm{m})$ & 174.19 & 163.90 & 165.33 & 163.14 & 166.08 & 1.59 & 0.17 \\
\hline Villus height/ crypt depth & 5.83 & 6.55 & 6.53 & 6.54 & 6.40 & 0.09 & 0.06 \\
\hline
\end{tabular}

AB- Antibiotic; MPE- Moringa plant extract; CBO- Clove bud oil; MPCBO- Moringa plant extract and clove bud oil; ${ }^{\mathrm{a}, \mathrm{b}}$ means with in a row with different superscripts are significantly different.; $*(\mathrm{p}<0.05)$ 
of duodenum, jejunum and ileum of experimental broiler birds did not differ significantly $(\mathrm{P}>0.05)$ among different treatment groups. Intestinal histomorphological studies showed significant difference $(\mathrm{P}<0.05)$ in villi height to crypt depth ratio of duodenum of experimental birds in MPE group in comparison to other groups. Villi height to crypt depth ratio of jejunum and ileum were tended to be higher ( $\mathrm{P}=0.07$ and $\mathrm{P}=0.06$ respectively) in antibiotic, Moringa plant extract and clove oil supplemented group than control.

\section{DISCUSSION}

Microbial status: Gut microbes have significant effects on host nutrition and health. Gut microbiome benefit the host by supplying nutrients and modulate development of digestive and immune system ( $\mathrm{Pan}$ and $\mathrm{Yu}, 2014$ ). $M$. oliefera leaf extracts has a potential role as an antibacterial and antioxidant (Sreelatha and Padma, 2009). Eugenol, a principal constituents of clove bud oil had good antibacterial activity against Listeria monocytogenes and Campylobacter jejuni but had medium antibacterial activity against Enterobacteria (Brenes and Roura, 2010). In the present experiment, Salmonella spp. and E. coli counts were not found significantly different $(\mathrm{P}>0.05)$ between groups. Lactobacillus spp. count was tended to be higher in supplemented groups. In agreement with the present study, Abd El-Ghany and Eraky, (2019) revealed that there was no significant $(\mathrm{P}>0.05)$ difference in total bacterial and Coliform count in intestine between control and $M$. oliefera supplemented group. Agostini et al. (2012) reported that Lactobacillus count were increased due to supplementation of clove bud oil in the diet of broilers, which could be due to positive selection of eugenol towards lactic acid bacteria. On contrary to our findings, Chowdhury et al. (2018) reported that Clostridium spp. counts reduced $(\mathrm{P}=0.029)$ in the antibiotic growth promoter group compared with the clove bud oil supplemented group and control and Lactobacilli spp. count was not affected $(\mathrm{P}=0.39)$ by any essential oil supplementation. Similarly, Gandomani et al. (2014) reported that incorporation of clove bud powder and fish oil either alone or in combination significantly $(\mathrm{p}<0.05)$ reduced the ileal Escherichia coli and Salmonella spp. counts.

Small intestinal morphology: The intestinal morphological characteristics in poultry are vital for nutrient utilization and indicate the sound physiology of the host. Longer villi are useful for better absorption of the nutrients due to more surface area and also indicators of improved gut health (Xu et al., 2003). In this experiment, VH/ $\mathrm{CD}$ ratio of duodenum of experimental birds in MPE group was significantly higher compared to other groups. Villi height to crypt depth ratio of jejunum and ileum were tended to be higher ( $\mathrm{P}=0.07$ and $\mathrm{P}=0.06$ respectively) in antibiotic, Moringa plant extract and clove oil supplemented group than control. These findings may have resulted from a controlled damage to the enterocytes, thus reducing the nutrient requirement for their turnover in $M$. oliefera and clove bud oil supplemented groups. This finding is in agreement with Khan et al. (2017) who observed that inclusion of $M$. oleifera leaf powder at $1.2 \%$ increased significantly $(\mathrm{P}<0.05) \mathrm{VD} / \mathrm{CD}$ ratio in ileum compared to control. On contrary, Acosta et al. (2018) reported that at 42 days, the height of villi of the duodenum of the control group obtained the lowest values with respect to M. oliefera supplemented groups. Chowdhury et al. (2018) revealed that the villi height in jejunum, duodenum and ileum was higher $(\mathrm{P}=0.04)$ in the cinnamon bark oil supplemented group than control, clove bud oil and ajwain oil groups, while no significant difference was found between cinnamon oil and antibiotic growth promoter in broiler chicken. Kavoi et al. (2016) observed that no significant differences $\mathrm{VH} / \mathrm{CD}$ ratio were noted between control and $M$. oleifera leaf meal supplemented birds. Gandomani et al. (2014) observed that feeding clove bud, at $2 \%$ level, increased in villus height, $\mathrm{VH} / \mathrm{CD}$ ratio, 
the number of lamina propria lymphatic follicles but decreased in crypt depth and goblet cells.

Considering the microbial status and intestinal morphology of the experimental broiler birds, it can be concluded that Moringa oliefera leaf extract

\section{REFERENCES}

Abd El-Ghany WA and Eraky RD, 2019. Influence of dietary Moringa oleifera on broilers performance, intestinal microbial population and humoral immune competence. J Hell Med Soc, 70(4): 18051810, doi: $10.12681 /$ jhvms. 22224

Acosta MR, Jiménez-Plasencia C, Woo CJ, Guízar JR, Espino AÁ et al., 2018. Inclusion of the Moringa oleifera leaf on immunological constants in broiler chickens. Abanico Veterinario, 8(3): 68-74

Agostini PS, Sola-Oriol D, Nofrarías M, Barroeta AC, Gasa J et al., 2012. Role of in-feed clove supplementation on growth performance, intestinal microbiology, and morphology in broiler chicken. Livest Sci, 147(1-3): 113-118, doi: 10.1016/j.livsci.2012.04.010

Brenes A and Roura E, 2010. Essential oils in poultry nutrition: main effects and modes of action. Anim Feed Sci Technol, 158(1-2): 1-14, doi: 10.1016/ j.anifeedsci.2010.03.007

Briozzo J, Núncez L, Chirife J, Herszage L and D'aquino M, 1989. Antimicrobial activity of clove oil dispersed in a concentrated sugar solution. J Appl Bacteriol, 66(1): 69-75, doi: 10.1111/j.13652672.1989.tb02456.x

Catala-Gregori P, Mallet S, Travel A and Lessire M, 2008. Efficiency of a prebiotic and a plant extract on broiler performance and intestinal physiology. $16^{\text {th }}$ European Symposium on Poult Nutrition, World Poultry Science Association, Strasbourg, France

CLSI (Clinical and Laboratory Standards Institute), 2008. Performance Standards for Antimicrobial Disk and Dilution Susceptibility Tests for Bacteria Isolated From Animals-Third Edition: Approved Standard M31-A3. CLSI, Wayne, PA, USA and clove bud oil have the potential to be used as an alternative to antibiotic growth promoter to improve the health status of broiler birds.

Conflict of interest: There is no conflict of interest.

Chowdhury S, Mandal GP, Patra AK, Kumar P, Samanta I et al., 2018. Different essential oils in diets of broiler chickens: 2. Gut microbes and morphology, immune response, and some blood profile and antioxidant enzymes. Anim Feed Sci Tech, 236: 39-47, doi: 10.1016/j.anifeedsci. 2017.12.003

David LS, Vidanarachchi JK, Samarasinghe K, Cyril HW and Dematawewa CMB, 2012. Effects of Moringa based feed additives on the growth performance and carcass quality of broiler chicken. J Trop Agric Res, 24(1): 12-20

Ehrlich J, Bauermann U and Thomann R, 1995. Antimicrobial effect of $\mathrm{CO}_{2}$ spice extracts. Lebensmitteltechnik (Germany), 27(11): 51-53

Feng J and Lipton JM, 1987. Eugenol: antipyretic activity in rabbits. Neuropharmacology, 26(12): 1775-1778, doi: 10.1016/0028-3908(87) 90131-6

Gandomani VT, Mahdavi AH, Rahmani HR, Riasi A and Jahanian E, 2014. Effects of different levels of clove bud (Syzygium aromaticum) on performance, intestinal microbial colonization, jejunal morphology, and immunocompetence of laying hens fed different n-6 to n-3 ratios. Livest Sci, 167: 236-248, doi: 10.1016/j.livsci.2014.05.006

Incharoen T, Khambualai O and Yamauchi K, 2009. Performance and histological changes of the intestinal villi in chickens fed dietary natural zeolite including plant extract. Asian J Poult Sci, 3(2): 42-50, doi: 10.3923/ajpsaj.2009.42.50

Kavoi BM, Gakuya DW, Mbugua PN and Kiama SG, 2016. Effects of dietary Moringa oleifera leaf meal supplementation on chicken intestinal structure and growth performance. J Morphol Sci, 33(4): 186-192, doi: 10.4322/jms.095915 
Khan I, Zaneb H, Masood S, Yousaf MS, Rehman HF et al., 2017. Effect of Moringa oleifera leaf powder supplementation on growth performance and intestinal morphology in broiler chickens. J Anim Physiol Anim Nutr, 101(S1): 114-121, doi: 10.1111/jpn.12634

Mehta LK, Balaraman R, Amin AH, Bafna PA and Gulati OD, 2003. Effect of fruits of Moringa oleifera on lipid profile of normal and hypercholesterolaemic rabbits. J Ethnopharmacol, 86(2-3): 191-195, doi: $10.1016 / \mathrm{S} 0378-8741(03) 00075-8$

Mitsch P, Zitterl-Eglseer K, Köhler B, Gabler C, Losa R et al. 2004. The effect of two different blends of essential oil components on the proliferation of Clostridium perfringens in the intestines of broiler chickens. Poult Sci, 83(4): 669675, doi: $10.1093 / \mathrm{ps} / 83.4 .669$

Najafi P and Torki M, 2010. Performance, blood metabolites and immuno-competence of broiler chicks fed diets included essential oils of medicinal herbs. J Anim Vet Adv, 9: 1164-1168

Pan D and Yu Z, 2014. Intestinal microbiome of poultry and its interaction with host and diet. Gut Microbes, 52(1): 108-119, doi: 10.4161/gmic. 26945
Snedecor GW and Cochran WG, 1994. Statistical methods, $6^{\text {th }}$ edn., Iowa State University

Sreelatha S and Padma PR, 2009. Antioxidant activity and total phenolic content of Moringa oleifera leaves in two stages of maturity. Plant Foods Human Nutr, 64(4): 303-311, doi: 10.1007/ s11130-009-0141-0

Suarez M, Haenni M, Canarelli S, Fisch F, Chodanowski $\mathrm{P}$ et al., 2005. Structure-function characterization and optimization of a plantderived antibacterial peptide. Antimicrob Agents Chemother, 49: 3847-3857, doi: 10.1128/ AAC.49.9.3847-3857.2005

Xu Z, Hu C, Xia M, Zhan X and Wang M, 2003. Effect of dietary fructooligosaccharide on digestive enzyme activities, intestinal microflora and morphology of male broilers. Poult Sci, 82(6): 1030-1036, doi: 10.1093/ps/82.6.1030

Yan L, Hong SM and Kim IH, 2012. Effect of bacteriophage supplementation on the growth performance, nutrient digestibility, blood characteristics, and fecal microbial shedding in growing pigs. Asian-Aust J Anim Sci, 25: 14511456, doi: 10.5713/ajas.2012.12253 